\title{
Schizophrenia Treatment Physician Order: New Initiatives at the Mental Hospital of Ministry of Health in Saudi Arabia
}

\author{
Yousef Ahmed Alomi ${ }^{1}{ }^{*}$ DD, Nora Alsolami², Nada Alqahtani ${ }^{3}$, Dalal Alqahtani ${ }^{4}$, Saeed Alqahtani ${ }^{5}$
}

${ }^{I}$ The Past General Manager of General Administration of Pharmaceutical Care Head, National Clinical Pharmacy and Pharmacy Practice Programs, Head, Pharmacy R and D Administration, Ministry of Health, Riyadh, SAUDI ARABIA.

${ }^{2}$ Head, Pharmaceutical Care Services, Al-Amel Medical Complex, Ministry of Health, Riyadh, Riyadh, SAUDI ARABIA.

${ }^{3}$ Head, Drug Information Services, Al-Amel Medical Complex, Ministry of Health, Riyadh, SAUDI ARABIA.

${ }^{4}$ Clinical Pharmacy Staff, Al-Amel Medical Complex, Ministry of Health, Riyadh, SAUDI ARABIA.

\section{Abstract}

The general administration of pharmaceutical care at the Ministry of Health in Saudi Arabia has released several pharmacy practice programs. The national pharmacy psychiatric program was one among them. This program has been established for the psychiatric management with an emphasis on schizophrenia. The guidelines in this program have been implemented in the form of a physician order form. This form consists of the best therapeutic choice for the conventional type of schizophrenia, or schizophrenia with comorbid disease. The schizophrenia guidelines have been approved by the medical staff and have been implemented at the hospital. This type of management of schizophrenia will prevent drug-related problems and improve clinical outcome of the patients. It is the first new initiative project at the Ministry of Health and in the Middle Eastern countries.

Key words: Schizophrenia Treatment, Physician Oder, Ministry of Health, Saudi Arabia.

Copyright: ( $)$ the author(s),publisher and licensee International Journal of Pharmacology and Clinical Sciences. This is an open-access article distributed under the terms of the Creative Commons Attribution Non-Commercial License, which permits unrestricted noncommercial use, distribution, and reproduction in any medium, provided the original work is properly cited.

This is an open access article distributed under the terms of the Creative Commons Attribution-NonCommercial-ShareAlike 4.0 License

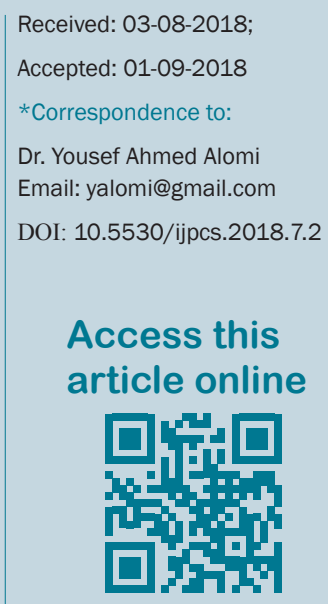

www.ijpcs.net

\section{INTRODUCTION}

The psychiatric healthcare services are well established in the Kingdom of Saudi Arabia. ${ }^{1-3}$ The pharmacy administration at the Ministry of Health has released several pharmacy practice programs including national pharmacy psychiatric program. This program consists of several elements including but not limited to the drug information services, medication safety programs, ambulatory care services, and evidence-based pharmacy guidelines. The pharmacy administration has shared information with the evidence-based healthcare center in Saudi Arabia and has published several guidelines with respect to the clinical practice in Saudi Arabia. ${ }^{4}$ Al-Amel Medical complex has established therapeutic guidelines as the physician order form. It was first hospital in Saudi Arabia implemented this model of the guidelines. Several publications have shown the benefit of psychiatric treatment guidelines worldwide. . $^{5-7}$ However, there is a scarcity of information regarding the psychiatric management guidelines in Saudi Arabia, Gulf, and Middle Eastern countries. Therefore, in this mini-review, we aimed to explore the new initiative's project on schizophrenia management physician order at Al-Amel Medical complex in Riyadh, Saudi Arabia. 
Schizophrenia Therapy order in Saudi Arabia

The schizophrenia physician order form consists of patient's demographic data, the type and stage of the disease, the first line of treatment used, the dose and duration of the therapy, and the second line of treatment if used. Followed by the comorbid disease with the primary disease with the appropriate choice for each combined disease. The prescription data and clinical pharmacist's data are recorded in the physician order form. The form can quickly be converted to an electronic format in the computer pharmacy system (Appendix 1).

\section{SWOT Analysis}

In this mini-review, we performed a Strengths, Weakness, Opportunities, and Threats (SWOT) analysis on the project data. Following were the strong points of the project: clinical pathway of psychiatric management, educational tool for new staff, fits the accreditation and requirements of accreditation boards and healthcare institutions, it controls hospital formulary, and prevents misuse of medications. The order forms did not cover all psychiatric diseases and all antipsychotic medications. The opportunities points were part of accreditation requirements and threads points were it not followed by healthcare staff, the new updating of the therapeutic guidelines.

\section{Implementation Steps of Schizophrenia Management Physician Order}

It is evidence-based setting up of psychiatric therapeutic guidelines at the most prominent mental hospital at the Ministry of Health in the Kingdom of Saudi Arabia. The guidelines are based on the recommendations of the American psychiatric society. It is designed by the pharmacy task force team and is headed by the author. The team consists of the head of the pharmacy, drug information pharmacist, four clinical pharmacists at acute and ambulatory care services and medications safety office, and inpatient and outpatient supervisor. The team is divided into three groups. Each group has different therapeutic management guidelines for common disorders such as depression, schizophrenia, and bipolar disorder. The first draft has been completed by the teams which covers physician order format by the first author. The therapeutic physician order has been revised by the three groups. The team has made several changes and discussion to reach the final agreement. The head of the pharmacy team submits the form to the pharmacy and therapeutic management teams for a final approval. The psychiatric therapeutic physician order is approved by the committee after several rounds of discussion and meeting. The guidelines are implemented through several educational sessions with the hospital staff. The manual physician order is then sent to the information technology team to convert it into an electronic format.

\section{CONCLUSION}

The schizophrenia management physician order is a new initiative in the Middle Eastern countries including the Kingdom of Saudi Arabia. This system is expected to improve patient outcome, prevent medication errors, and reduce the economic burden in Saudi Arabia.

\section{ACKNOWLEDGEMENT}

None.

\section{CONFLICT OF INTEREST}

None.

\section{ABBREVIATIONS}

KSA: Kingdom of Saudi Arabia; MOH: Ministry of Health, SWOT: Strengths, Weakness, Opportunities, and Threats

\section{ORCID ID}

Yousef Ahmed Alomi iD https://orcid.org/0000-0003$1381-628 \mathrm{X}$

\section{REFERENCES}

1. Qureshi NA, Al-Habeeb AA, Koenig HG. The mental health system in Saudi Arabia: an overview. Neuropsychiatr Dis Treat. 2013;9:1121-35.

2. Koenig HG, Zaben F Al, Sehlo MG, Khalifa DA, Shaheen M, Ahwal A, et al. Mental Health Care in Saudi Arabia : Past, Present and Future. Open J Psychiatry 2014; 4:113-30.

3. Almutairi AF. Mental illness in Saudi Arabia: an overview. Psychol Res Behav Manag. 2015; 8:47-9.

4. Ministry of Health. The Saudi center for evidence-based healthcare (EBHC) [Internet]. 2014 [cited 2017 Sep 24]. Available from: http://www.moh.gov. sa/endepts/Proofs/Pages/home.aspx

5. Katon W, Korff MV, Lin E, Walker E, Simon GE, Bush T, et al. Collaborative Management to Achieve Treatment Guidelines. JAMA. 1995;273(13):1026.

6. Citrome L, Yeomans D. Do guidelines for severe mental illness promote physical health and well-being?. J Psychopharmacol. 2005;19(6 Suppl):102-9.

7. Niederkrotenthaler T, Sonneck G. Assessing the Impact of Media Guidelines for Reporting on Suicides in Austria: Interrupted time Series Analysis. Aust New Zeal J Psychiatry. 2007;41(5):419-28. 